\title{
A IDEIA DE ESCRAVIDÃO PRESENTE NA NARRATIVA DE MANUAIS DIDÁTICOS DE HISTÓRIA
}

\author{
Rosi Terezinha Ferrarini Gevaerd* \\ rosifgevaerd@yahoo.com.br
}

\begin{abstract}
Resumo: Esta investigação insere-se no Grupo de Pesquisa em Educação Histórica vinculado ao Laboratório de Pesquisa em Educação Histórica - LAPEDUH, integrado ao Programa de Pós-Graduação em Educação da Universidade Federal do Paraná, sob a coordenação da Profa. Dra. Maria Auxiliadora Schmidt. Para este artigo destaco a pesquisa que estou desenvolvendo e que parte da seguinte questão de investigação: De que forma a ideia de escravidão está presente na narrativa de manuais didáticos de história das séries iniciais do ensino fundamental? Inicialmente, a pesquisa consistiu em análise documental de Manuais didáticos do PNLD/2010, 2. ${ }^{\circ}$ ao $5 .^{\circ}$ ano do ensino fundamental. Em seguida, busquei ver se, para as professoras, $o$ manual adotado na escola pode ser considerado "um bom livro de História" a partir da perspectiva de Rüsen (1997) e Medeiros (2005).
\end{abstract}

Palavras-Chaves: Educação histórica, Manuais didáticos PNLD, Ideia de Escravidão.

INTRODUÇÃO

O Projeto "Aprender a ler e aprender a escrever em História", aprovado como bolsa produtividade do Conselho Nacional de Desenvolvimento Científico e Tecnológico (CNPQ), 2009-2012, constitui uma das ações do conjunto de atividades do Laboratório de Pesquisa em Educação Histórica (LAPEDUH), integrado ao Programa de Pós-Graduação em Educação da

* Doutora em Educação pela Universidade Federal do Paraná (2009), contou com a orientação da Profa. Dra. Maria Auxiliadora Moreira dos Santos Schmidt; Pós-Doutorado - UFPR, Núcleo de Pesquisas em Publicações Didáticas (NPPD), com a supervisão da Profa. Dra. Tânia Maria Figueiredo Braga Garcia, 2011/2012 (em processo). Professora de História da Rede Municipal de Ensino de Curitiba. Atua na Secretaria Municipal da Educação com a formação continuada de professores. Uma primeira versão dessa pesquisa foi apresentada no V Simpósio Internacional de História - Culturas e Identidades - ANPUH/GO, realizado na UFG em 2011. 
Universidade Federal do Paraná (UFPR), sob a coordenação da Profa. Dra. Maria Auxiliadora Moreira dos Santos Schmidt.

No conjunto destas ações está o "Grupo de Pesquisa em Educação Histórica" ${ }^{1}$ que tem como um dos objetivos centrais reunir um grupo de pesquisadores ${ }^{2}$, mais especificamente, doutores e mestres com trabalhos já defendidos, para levantamento de dados comparativos entre Brasil e outros países que realizam pesquisas em Educação Histórica.

Estas pesquisas têm tomado como foco um conjunto de investigações sobre a forma como a narrativa histórica escolarizada tem tratado a temática da escravidão no Brasil e sua relação com a formação da consciência histórica de jovens escolarizados, tendo como pressupostos teóricos os princípios específicos da Educação Histórica, especialmente, os que fundamentam as investigações que têm como preocupação os estudos sobre formação de consciência histórica, como os trabalhos de Lee (2001; 2003); Rüsen (2001; 2007); Schmidt (2002; 2006); Schmidt e Garcia (2006); Schmidt e Barca (2009), entre outros.

Para nortear as pesquisas levantou-se a seguinte questão de investigação: De que forma a instituição de determinadas narrativas históricas pela história escolarizada tem contribuído para a formação da consciência histórica sobre a escravidão no Brasil?

Os pesquisadores têm investigado a temática em pauta em produtos da cultura escolar e nas ideias de alunos e professores ${ }^{3}$, tais como: Revistas de História (paradidáticas); Publicações acadêmicas de História (Anais); Manuais didáticos do Ensino Fundamental e Médio (Programa Nacional do Livro Didático - PNLD); Questões de vestibular; Ideias de escravidão em alunos do ensino básico; Ideias de escravidão em professores de história do ensino básico.

Para esta comunicação apresento alguns resultados da pesquisa que estou desenvolvendo no grupo. Para empreender a investigação defini os seguintes objetivos: Identificar se o conceito substantivo escravidão está presente nas narrativas dos livros didáticos do PNLD/2010; Identificar as ideias expressas pelos alunos em relação ao conceito substantivo escravidão.

Diante disso, delineei a seguinte questão de investigação: "De que forma a ideia de escravidão está presente na narrativa de manuais didáticos de história das séries iniciais do ensino fundamental?"

A partir disso, delimitei o campo de investigação. Uma escola da Rede Municipal de Ensino de Curitiba, turmas de $4^{\circ}$ e $5^{\circ}$ anos do ensino fundamental, com alunos entre 8 e 11 anos de idade, na medida em que atuo com a formação continuada de professores desta rede de ensino. 
A metodologia de pesquisa consistiu em análise documental dos livros didáticos das séries iniciais, PNLD/2010, para identificar a presença, ou não, do conceito substantivo escravidão; questionário para os professores; questionário para os alunos; produção de narrativas pelos alunos; observação não-participativa, ou seja, acompanhar as aulas de história das referidas turmas, durante a aula que trata do conceito substantivo escravidão, sem interferência nas aulas das professoras.

\section{PRESSUPOSTOS TEÓRICOS}

$\mathrm{Na}$ esteira dos estudos das disciplinas escolares ${ }^{4}$, Cuesta Fernandes, que tem buscado como fontes os manuais e os programas escolares, os denomina de textos visíveis do código disciplinar da história escolar (CUESTA FERNANDEZ, 1997, p. 12,13).

Além dos textos visíveis, segundo o autor, há que se buscar outras fontes para a reconstrução do código disciplinar do ensino de História. Seriam os textos invisíveis do código disciplinar, "os conteúdos escolares da prática de ensino". Deste modo, para essa reconstrução há que se "diversificar" as fontes: "fotografia, pintura, espaços e arquiteturas escolares, regulamentos, memórias de centros, testemunhos orais, entrevistas, informes administrativos etc." Todavia, para se obter essa diversidade de material é necessário um "custoso esforço de descobrimento, recompilação e reconstrução" de informações para poder "encaixar as peças deste quebra-cabeças que é o código disciplinar da História." (CUESTA FERNANDEZ, 1997, p. 21).

Para este autor, código disciplinar ${ }^{5}$ é:

Uma tradição social que se configura historicamente e que se compõe de um conjunto de idéias, valores, suposições e rotinas, que legitimam a função educativa atribuída à História e que regulam a ordem da prática de seu ensino. O código disciplinar da História, alberga, pois, as especulações e retóricas discursivas sobre seu valor educativo, os conteúdos de ensino e os arquétipos da prática docente, que se sucedem no tempo e que se consideram, dentro da cultura, valiosos e legítimos. (CUESTA FERNANDEZ, 1997, p. 20)

Para o autor o manual didático constitui um gênero literário que se constrói historicamente e que possui marcas que permitem diferenciá-lo de outros instrumentos de comunicação verbal. Todo manual didático possui algumas chaves pedagógicas explícitas ou tácitas e define, direta ou indiretamente, um modelo didático. 
O autor entende o texto didático como:

o conjunto de suposições e normas tangíveis ou intangíveis, visíveis ou invisíveis, que governam seu discurso e seu uso: desde a freqüente adoção de um estilo frio e impessoal, como se não existisse o aluno, como se a narração fosse transescolar, até a seqüência de atividades e a atribuição de papéis aos intervenientes no processo de ensino e aprendizagem (CUESTA FERNANDEZ, 1998, p.107).

Nesse sentido, o manual didático possui uma "marca pedagógica", ou seja, as relações entre texto escrito e visual, a existência de partes dedicadas a recapitular o texto principal, os esquemas e gráficos. Esses elementos estão, habitualmente, colocados ao final de cada tema, e são conhecidos como os "questionários de estudo", nos quais são propostas perguntas para confirmar o que foi estudado, e que servem para memorizar uma determinada interpretação histórica, sugerindo, outras vezes, um conjunto de "atividades de análises e de aplicação", com a intenção de aplicar o estudo, mediante atividades e questões de diferentes categorias, por exemplo: "Explique as diferenças entre.... (CUESTA FERNANDEZ, 1998, p.109).

Este esquema formal contém em seu interior um "subentendido pedagógico" da representação da história em aula, sendo que o ponto principal é o discurso já "acabado" da história e sobre o qual deve "versar a explicação do professor” (CUESTA FERNANDEZ, 1998, p.110).

Os primeiros manuais didáticos de história, de acordo com Cuesta Fernandez (1998, p.112), revivem esquemas básicos da antiga história universal. O programa em que se inspiravam impõe aos textos "uma concepção linear, diacrônica e eurocêntrica do devir histórico". O tipo de ensino proposto nesses livros resultava da tradição da "História sem pedagogia", ou seja, o pedido de explicação ao aluno ao final da lição, sendo que as atividades são mero complemento ou reforço do discurso do professor, de suas explicações ou, o que é o mesmo, do texto escrito que figura como trama narrativa central das lições.

Do ponto de vista do modelo didático, Cuesta Fernandez (1998, p.115116), observa que houve algumas mudanças desde os primeiros manuais até a década de 1970, em que os documentos e fontes figuravam em uma posição marginal, e na década de 1980, em que o espaço dedicado aos documentos históricos começa a competir com o espaço assegurado ao discurso narrativo. As imagens, aos poucos, deixam de desempenhar uma função "vicária" do texto e tornam-se uma categoria componente do aparelho pedagógico 
dos novos manuais. Cada vez mais, o manual didático propõe aos alunos atividades de análise e uso de documentos históricos.

Desse modo, diz Cuesta Fernandez (1998, p.116), os novos manuais didáticos apresentam uma ambivalência: por um lado, continuam utilizando como ponto central o discurso histórico em um texto narrativo impessoal de tipo objetivo e, por outro, apresentam fontes e documentos históricos de todo tipo, propondo atividades que recriam os procedimentos adotados pelos historiadores e sua forma de pensar.

No entanto, o manual didático, ainda que em sua versão mais avançada, segue sendo exemplar de um "saber fossilizado" e de uma determinada maneira de aprender e de ensinar história (CUESTA FERNANDEZ, 1998, p.116-117).

Além disso, neste trabalho o manual didático está sendo tomado na perspectiva dos estudos de Circe Bittencourt (2001). Segundo esta autora, desde o século XIX, o manual didático tem sido um importante instrumento utilizado em sala de aula, na medida em que tem servido "como mediador entre a proposta oficial do poder expressa nos programas curriculares e o conhecimento escolar ensinado pelo professor" (BITTENCOURT, 2001, p.72).

O manual didático passa pela intervenção do professor e dos alunos que realizam práticas diferentes de leitura e de trabalho escolar. Os usos que professores e alunos fazem do livro didático são variados, podendo tornar-se um instrumento de trabalho mais eficiente e adequado às necessidades de um ensino autônomo. Mesmo que o manual didático se caracterize pelo texto "impositivo e diretivo", a atuação do professor é fundamental, na medida em que define a sua forma de uso, pois cabe ao professor, na maioria das vezes, a escolha do livro, os capítulos a serem trabalhados, a metodologia adotada para a leitura - em grupo ou individual, assim como as tarefas decorrentes da leitura, que são opções exclusivas do professor (BITTENCOURT, 2001, p.73-74).

Além de um "depositário dos conteúdos escolares" e um "instrumento pedagógico", como indicado por Cuesta Fernandez (1998), o manual didático é considerado, no dizer de Bittencourt (2001, p.71-72), como uma "mercadoria”, na medida em que é um produto de edição que segue as tendências de fabricação e comercialização obedecendo à lógica do mercado. Ademais, é um "veículo portador de um sistema de valores, de uma ideologia, de uma cultura", ou, nas palavras de Cuesta Fernandez (1998, p.28), um instrumento de "inculcação ideológica”. De acordo com Abud (1984, p.81), o manual didático tem sido um dos canais de transmissão e, sobretudo, de "manutenção dos mitos e estereótipos" da história. 
Ainda, neste trabalho, parto dos estudos de Peter Lee (2001; 2005), no que se refere aos conceitos substantivos da história presentes em aulas de história, nesse caso, o conceito de escravidão.

Conceitos substantivos da história, diz Lee (2005, p.61), são conceitos como comércio, nação, protestante, escravo, tratado ou presidente, e são encontrados quando trabalhamos com tipos particulares de conteúdos históricos. Eles são parte do que podemos chamar de substância da história e, por isso, têm sido denominados conceitos substantivos. Tais conceitos pertencem a diferentes tipos de atividade humana, como a econômica, a política, a social e a cultural.

Tendo como referencial teórico este conjunto de autores a fase inicial da pesquisa consistiu em análise documental de Manuais didáticos do $\mathrm{PNLD} / 2010,2^{\circ}$ ao $5^{\circ}$ ano do ensino fundamental, para em seguida, buscar ver as ideias de alunos e professores em relação ao conceito escravidão em Escolas da Rede Municipal de Ensino de Curitiba (RME).

\section{Percurso metodológico}

Em janeiro de 2003, é assinada pelo presidente Luiz Inácio Lula da Silva, a Lei 10.639/03, que torna obrigatório o ensino da história e cultura afro-brasileira em todos os estabelecimentos de ensino da educação básica (BRASIL, 2003).

Segundo, Luiz Carlos Paixão da Rocha (2010, p.1): Apesar de o movimento social negro considerar a lei como uma importante conquista, estudos recentes têm apontado enormes dificuldades para a efetivação da nova legislação em todo o país. Em vigor há mais de seis anos, a mesma, ainda não conseguiu dar início a um processo mais consistente de alteração da cultura da discriminação presente na maioria das escolas brasileiras.

No entanto, a determinação da lei acabou por refletir-se em mudanças significativas no Programa Nacional do Livro Didático - PNLD (BRASIL, 2009). Na área de História, de acordo com a equipe de avaliação do Programa, um marco relevante foi o estabelecido pela referida lei, assim como a Lei $\mathrm{n}^{\circ} 11.645$ de 2008 (BRASIL, 2008), sobre a obrigatoriedade da História e da Cultura Afro-Brasileiras e Indígenas como conteúdo escolar, na medida em que uma das aplicações destas leis é a "obrigatoriedade de os livros escolares da disciplina tratarem de temas da História da África e 
da participação de afrodescendentes e indígenas na sociedade brasileira” (BRASIL, 2009, p.11).

A partir desta determinação, busquei identificar se o conceito substantivo escravidão está indicado a ser ensinado como um conteúdo escolar. Para tanto, fiz o levantamento dos títulos dos manuais avaliados e aprovados pelo PNLD/2010 para as séries iniciais do ensino fundamental e apresentados no Guia do Livro Didático de História (BRASIL, 2009).

Após análise das 32 coleções $^{6}$, constatei que o conceito está indicado, em alguns anos de escolarização, de forma implícita e, em outros, de forma explícita, conforme quadro abaixo:

\section{Conceito escravidão}

\begin{tabular}{l|l}
\hline Indicado de forma implícita & Indicado de forma explícita \\
\hline $2^{\circ}$ ano -03 & $5^{\circ}$ ano -11 \\
\hline $3^{\circ}$ ano -02 & $4^{\circ}$ e $5^{\circ}$ ano -07 \\
\hline $4^{\circ}$ ano -03 & $4^{\circ}$ ano -04 \\
\hline $5^{\circ}$ ano -02 & \\
\hline $2^{\circ}$ e $5^{\circ}$ ano -01 & \\
\hline $3^{\circ}$ e $4^{\circ}$ ano -01 & \\
\hline $4^{\circ}$ e $5^{\circ}$ ano -02 & \\
\hline $2^{\circ}, 3^{\circ}$ e $5^{\circ}$ ano -01 & \\
\hline
\end{tabular}

Constatei que nas 32 coleções o conceito está indicado como conteúdo a ser ensinado, com maior ênfase e de forma explícita, nos $4^{\circ}$ e $5^{\circ}$ anos. Em 11 (onze) coleções o conceito está indicado no $5^{\circ}$ ano; em 04 (quatro) está indicado no $4^{\circ}$ ano e em 07 (sete) coleções está indicado no $4^{\circ}$ e $5^{\circ}$ anos.

Em seguida, analisei as narrativas destes manuais didáticos e constatei que as ideias mais recorrentes são: “... submetidos a trabalhos forçados e maus-tratos"; “...vieram para o Brasil forçados, como escravos"; "Desde o começo os escravos reagiram contra a escravidão...." e de "Em busca da liberdade: luta e resistência..., entre outras. 
Tendo identificado as ideias expressas nos manuais em relação ao conceito escravidão, obtive a seguinte categorização:

\section{Categorias}

\begin{tabular}{l|l}
\hline \multicolumn{1}{l}{ Ideais mais recorrentes } \\
\hline $\begin{array}{l}\text { Os povos que vie- } \\
\text { ram da África }\end{array}$ & $\begin{array}{l}\text { "A gente que veio da África..." } \\
\text { "Os africanos... } \\
\text { "Um pouco sobre a história da África..." }\end{array}$ \\
\hline Trabalho escravo & $\begin{array}{l}\text { "... submetidos a trabalhos forçados e maus-tratos..." } \\
\text { “...vieram para o Brasil forçados, como escravos..." }\end{array}$ \\
\hline Luta e resistência & $\begin{array}{l}\text { "Desde o começo os escravos reagi- } \\
\text { ram contra a escravidão...." } \\
\text { "Em busca da liberdade: luta e resistência..." } \\
\text { "Quilombos: resistência à escravidão..." } \\
\text { "Uma história de luta e resistência..." } \\
\text { "Afro-brasileiros: uma história de luta..." } \\
\text { "Havia quilombos em todo o Brasil, e eles sig- } \\
\text { nificavam um ponto de resistência à escravi- } \\
\text { dão; por isso, foram duramente combatidos." }\end{array}$ \\
\hline $\begin{array}{l}\text { Formação do povo } \\
\text { brasileiro/cultu- } \\
\text { ra brasileira }\end{array}$ & $\begin{array}{l}\text { "A cultura brasileira mantém traços marcantes da } \\
\text { música, da culinária e da religião africana e absor- } \\
\text { vem palavras que hoje fazem parte da nossa língua." } \\
\text { "A contribuição negra está presente em vários } \\
\text { aspectos de nossa vida, por exemplo, na culiná- } \\
\text { ria, na música, na dança e na religiosidade." } \\
\text { "Quando vieram da África, como escravos para } \\
\text { o Brasil, os negros trouxeram muitos costumes } \\
\text { da sua terra. Morando aqui eles mudaram seu } \\
\text { jeito de viver, mas continuaram a participar de } \\
\text { festas com jogos, danças e batuques. Um desses } \\
\text { jogos praticados pelos negros é a capoeira." }\end{array}$ \\
\hline
\end{tabular}

Pude constatar que, de modo geral, estas narrativas estão muito próximas das narrativas de historiadores clássicos da historiografia brasileira, pois como aponta Adriane Sobanski (2008) em sua dissertação de mestrado7, "O que temos constatado é que sobre a História da África ainda pesam as mesmas referências culturais idealizadas e defendidas por teóricos como Oliveira Viana, Nina Rodrigues e Gilberto Freyre orientando as interpretações de um passado tido como único e verdadeiro". 
Isto me levou a buscar na historiografia brasileira se existem algumas aproximações entre as narrativas destes autores e a narrativa do manual didático.

Exemplo:

Na narrativa do manual didático:

2 A sociedade mineradora

A extração do ouro era feito por escravos

(...)

O trabalho de extração do ouro era muito duro e, geralmente, feito por escravos. Muitos deles contraíam doenças respiratórias, pois passavam grande parte do dia com os pés na água. (Costa Junior, 2007, 5º ano, p.26). (Grifo do autor).

Na narrativa do historiador:

Nina Rodrigues - Os africanos no Brasil ${ }^{8}$ :

A escravidão negra no Brasil é, pois, contemporânea da sua colonização. Somente ela guardou, nos primeiros tempos, a feição portuguesa de fenômeno secundário, limitado ao serviço doméstico. Surgiu como problema brasileiro quando, faltando o índio, que sucumbia ou era protegido pelos jesuítas, e começando a escassear os braços para a lavoura e, mais tarde, para o trabalho das minas, se criou um comércio de escravos direto, entre a nova Colônia e a África. (1976, p.14). (Grifo meu).

Nesta narrativa fica evidenciada a presença de alguns elementos da historiografia clássica nos manuais didáticos.

Estas análises estão em fase de realização, portanto, não podendo ainda ser apresentadas com maior especificidade.

Concomitante a isto, após a análise das 32 coleções do PNLD/2010, optei por um recorte. Identificar os manuais adotados nas escolas da Rede Municipal de Ensino de Curitiba. Após levantamento, obtive os seguintes resultados: das 168 escolas que escolheram manuais didáticos do PNLD/2010, das 32 coleções, 19 foram escolhidas. Sendo que a mais escolhida, por 30 escolas, foi A Coleção PROJETO BURITI: HISTÓRIA (COSTA JUNIOR, 2007).

A partir deste levantamento definiu-se a escola ${ }^{9}$ para realizar a investigação, ou seja, uma das escolas que recebeu o livro mais adotado nas escolas municipais. Constituindo-se, portanto, no campo de pesquisa deste estudo.

Após permissão oficial da Secretaria Municipal da Educação realizou-se o contato com a referida escola e, em seguida, conversa com as professoras 
para explicar o motivo e procedimentos da minha investigação. Abaixo, quadro com os dados profissionais e acadêmicos das professoras de $4^{\circ}$ ano e $4^{\text {a }}$ série $^{10}$, regentes e corregentes:

\begin{tabular}{|c|c|c|c|c|c|}
\hline Nome & $\begin{array}{l}\text { Ano/série/ } \\
\text { Turma }\end{array}$ & Graduação & Especialização & $\begin{array}{l}\text { Iniciou suas } \\
\text { atividades } \\
\text { docentes }\end{array}$ & $\begin{array}{l}\text { Atuação } \\
\text { neste ano } \\
\text { de escola- } \\
\text { rização }\end{array}$ \\
\hline Sandra & $4^{\circ}$ ano $\mathrm{A}$ & $\begin{array}{l}\text { Normal } \\
\text { Superior }\end{array}$ & $\begin{array}{l}\text { Educação } \\
\text { Especial }\end{array}$ & 1992 & 2008 \\
\hline Jussara & $4^{\circ}$ ano $\mathrm{B}$ & $\begin{array}{l}\text { Ciências e } \\
\text { Matemática; } \\
\text { Pedagogia }\end{array}$ & $\begin{array}{l}\text { Alfabetização; } \\
\text { Matemática } \\
\text { Infantil; } \\
\text { Psicologia } \\
\text { (cursando) }\end{array}$ & 1992 & 1992 \\
\hline Marina & $\begin{array}{l}4^{\circ} \text { s anos } \\
\text { (corregente) }\end{array}$ & $\begin{array}{l}\text { Pedagogia; } \\
\text { Normal } \\
\text { Superior }\end{array}$ & & 1989 & 2007 \\
\hline Ana & $4^{\mathrm{a}}$ série $\mathrm{A}$ & $\begin{array}{l}\text { Educação } \\
\text { Artística }\end{array}$ & $\begin{array}{l}\text { Arte e } \\
\text { Educação } \\
\text { Curso de } \\
\text { extensão: } \\
\text { História da } \\
\text { África - UFPR }\end{array}$ & $\begin{array}{l}1980 \\
\text { (aposentada); } \\
\text { reiniciou } \\
\text { em } 2009\end{array}$ & 2005 \\
\hline Marcia & $4^{a}$ série $B$ & Sociologia & $\begin{array}{l}\text { Psicopedagogia; } \\
\text { Teologia }\end{array}$ & 1985 & 2005 \\
\hline Andrea & $4^{\mathrm{a}}$ série $\mathrm{C}$ & Pedagogia & 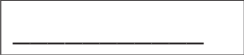 & 2003 & 02 meses \\
\hline Laura & $\begin{array}{l}4^{\text {a s séries }} \\
\text { (corregente) }\end{array}$ & $\begin{array}{l}\text { Educação } \\
\text { Artística }\end{array}$ & $\begin{array}{l}\text { Estética de } \\
\text { Arte - Teatro }\end{array}$ & 1982 & 1981 \\
\hline
\end{tabular}

Das 07 (sete) professoras entrevistadas, 02 (duas) são de $4^{\circ}$ ano; 03 (três) são de $4^{\text {a }}$ série; 02 (duas) são corregentes ${ }^{11}$.

Quanto à formação acadêmica, as professoras possuem formação superior. Sendo que 02 (duas) em mais de um curso. Concentram-se 03 (três) em Pedagogia, 02 (duas) em Educação Artística; 01 (uma) em Ciências e Matemática; 01 (uma) em Sociologia; 01 (uma) Normal Superior.

Das 07 (sete) professoras, de modo geral, todas tem bastante tempo de experiência profissional, próximo de 20 anos. Somente uma professora possui pouco tempo de serviço, 07 (sete) anos. 
Além destas informações, foi solicitado às professoras que preenchessem um questionário. O objetivo foi para saber se, na opinião delas, $o$ livro adotado e recebido pela escola é um "Bom Livro de História". Para isto, utilizei os critérios apontados por Rüsen (1997) em relação às condições para um bom Livro de História e categorizadas por Medeiros (2005): Utilidade para o ensino prático; Utilidade para a percepção histórica; Utilidade para a interpretação histórica e Utilidade para a orientação histórica.

Quando perguntado: Se já haviam trabalhado com este livro? Todas afirmaram que sim. A seguir, os conteúdos trabalhados pelas professoras:

\begin{tabular}{|c|c|}
\hline $\begin{array}{l}\text { Professora } \\
\text { Ano/ Série }\end{array}$ & Conteúdos trabalhados \\
\hline $\begin{array}{l}\text { Sandra } \\
4^{\circ} \text { ano A }\end{array}$ & $\begin{array}{l}\text { Os antigos povos indígenas; A época das grandes na- } \\
\text { vegações; A chegada ao Brasil, dos portugueses. }\end{array}$ \\
\hline $\begin{array}{l}\text { Jussara } \\
4^{\circ} \text { ano B }\end{array}$ & $\begin{array}{l}\text { Povos indígenas do Brasil; Aventura dos navegado- } \\
\text { res portugueses; Os povos que vieram da África. }\end{array}$ \\
\hline $\begin{array}{l}\text { Ana } \\
4^{a} \text { série } \mathrm{A}\end{array}$ & $\begin{array}{l}\text { Análise das gravuras (livro adotado) } \\
\text { Trabalhou com o livro História do Paraná - Indígenas. }\end{array}$ \\
\hline $\begin{array}{l}\text { Marcia } \\
4^{\text {a }} \text { série B }\end{array}$ & Paraná: passado e presente; Indígenas. \\
\hline $\begin{array}{l}\text { Andrea } \\
4^{\mathrm{a}} \text { série } \mathrm{C}\end{array}$ & A expansão da Colônia. \\
\hline
\end{tabular}

As professoras trabalharam com o manual didático recebido na escola. Constatei que o conteúdo mais abordado foi a questão dos Indígenas, sendo que 04 (quatro) professoras já haviam trabalhado este conteúdo. Os demais conteúdos trabalhados foram: A questão das grandes navegações trabalhada por 02 (duas) professoras; A chegada ao Brasil por 01 (uma); Os povos que vieram da África por 01 (uma); A expansão da Colônia por 01 (uma) professora.

A segunda questão: Você já trabalhou o conteúdo histórico "Escravidão" neste ano? Caso negativo. Você concordaria em investigar os conhecimentos prévios de seus alunos sobre este conteúdo histórico?

A professora Ana comentou que "Sim, já houve introdução ao conteúdo”, mas que gostaria de investigar os conhecimentos prévios de seus alunos para "saber o que eles haviam aprendido". As demais professoras, não haviam trabalhado este conteúdo e concordaram em aplicar o instrumento de pesquisa com seus alunos. Este procedimento foi realizado no decorrer do $2^{\circ}$ semestre de 2010 . 
A atual fase da pesquisa consiste em analisar as opiniões expressas pelas professoras. Algumas ideias foram apontadas, entre elas, a da professora Marcia que diz: "Percebo que os textos estão acima da compreensão das crianças".

\section{CONSIDERAÇÕES FINAIS}

Algumas considerações podem ser apontadas, entre elas, a de que o conceito substantivo escravidão está indicado de forma explícita nos manuais didáticos do $\mathrm{PNLD} / 2010$, mais especificamente, nos volumes para o $4^{\circ}$ e $5^{\circ}$ anos de escolarização.

De modo geral, as narrativas dos manuais didáticos sugerem uma forte presença da perspectiva clássica da historiografia brasileira tendo como referência autores como Oliveira Viana, Nina Rodrigues e Gilberto Freyre.

Em relação ao manual didático recebido na escola municipal pesquisada, PROJETO BURITI: HISTÓRIA, constatei que este é usado na sala de aula. De modo geral, as professoras consideram que este manual didático deveria: "aprofundar mais os conteúdos", "ter um maior detalhamento dos textos", "apresenta poucas sugestões de leituras", "apresenta poucos documentos históricos", entre outras questões.

No entanto, constatei que este não é o único manual usado em aulas de história. Segundo as professoras, elas utilizam, também, o que trata da História do Paraná, de autoria de Graziella Rollemberg, recebido do PNLD/2010, pois no entender delas "este é mais acessível para os alunos".

Nesse sentido, pode-se dizer que o manual didático de história tem sido usado pelas professoras constituindo-se no texto visível do código disciplinar da história escolar de acordo com Cuesta Fernandes (2007), pois, segundo este autor, este material tem sido considerado como uma importante fonte de divulgação científica e, portanto, uma das formas adequadas para se ensinar e aprender História.

A partir dessas considerações, ainda que parciais, destaco que esta pesquisa está em andamento e os dados coletados serão utilizados no estudo exploratório durante a investigação a ser desenvolvida no Pós-Doutorado na UFPR, mais especificamente, junto ao Núcleo de Pesquisas em Publicações Didáticas (NPPD), na medida em que os investigadores do referido núcleo têm desenvolvido ações de extensão e pesquisa relacionadas ao uso do manual didático, foco de minha investigação. 
THE IDEA OF SLAVERY PRESENT AT THE NARRATIVE OF HISTORY TEXTBOOKS

Aвstract: This investigation is inserted in the Group of Research on Historical Education linked to the Laboratory of Research in Historical Education (Laboratório de Pesquisa em Educação Histórica - LAPEDUH) integrated to the Post-Graduation Program in Education from the Federal University of Paraná, under the coordination of Prof. Dr. Maria Auxiliadora Schmidt. For this communication I will highlight the research I am developing which starts from the following research question: In what way is the concept of slavery present in the narratives from history didactic manuals belonging to the beginning grades of basic education? Initially, the research consisted of documental analysis of Didactic manuals from the PNLD/2010 (Brazilian National Program of Didactic Manuals) from $2^{\text {nd }}$ to $5^{\text {th }}$ grades of basic education. After that, I tried to see if, for the teachers, the manual adopted in the school could be considered "a good History book" from the perspective of RÜSEN (1997) and MEDEIROS (2005).

KEY wORDs: Historical education, Didactic manuals from the PNLD, Concept of Slavery.

NOTAS

1 No $1^{\circ}$ semestre de 2010, durante o Seminário realizado sob a coordenação da Profa. Maria Auxiliadora Schmidt, com os professores do Programa de Desenvolvimento Educacional (PDE) - Programa de Governo do Estado do Paraná -, surgiu uma demanda por parte destes professores em relação à discussão da questão da escolha dos manuais didáticos do PNLD/2011. Nesse sentido, ocorreu a ampliação do projeto do "Grupo de Pesquisa em Educação Histórica", numa perspectiva de projeto colaborativo - professores da rede pública e privada e os pesquisadores do referido grupo. Este processo está sendo implementado no $2^{\circ}$ semestre deste ano, para que os resultados destas discussões sejam apresentadas no $3^{\circ}$ Seminário de Educação Histórica, a ser realizado em novembro do ano em curso, na UFPR.

2 Dra. Ana Cláudia Urban, Rede Estadual de Ensino do Paraná e Faculdade Sant’Ana - Ponta Grossa; Dr. Daniel Hortêncio de Medeiros, Universidade Positivo; Dr. Geyso Dongley Germinari, Pesquisador UFPR/LAPEDUH; Dra. Marlene Terezinha Grendel, Rede Municipal de Ensino de Araucária e Rede Estadual de Ensino do Paraná; Dra. Rosi Terezinha Ferrarini Gevaerd, Rede Municipal de Ensino de Curitiba; Ms. Alamir Muncio Compagnoni, Rede Municipal de Ensino de Araucária; Ms. Adriane de Quadros Sobanski, Rede Estadual de Ensino do Paraná e Rede Particular de Ensino do Paraná; Ms. Henrique Rodolfo Theobald, Rede Municipal de Ensino de Araucária; Ms. Lilian Costa Castex, Rede Municipal de Ensino de Curitiba; Ms. Lindamir Zeglin, Rede Municipal de Ensino de Araucária. 
3 Alguns resultados destas investigações foram apresentados no $1^{\circ}$ Colóquio do Grupo de Pesquisa em Educação Histórica, com a temática Escravidão: Perspectivas da Educação Histórica, realizado no dia 12 de junho, na UFPR.

4 Autores que têm discutido a questão: CHERVEL, A. História das disciplinas escolares: reflexões sobre um campo de pesquisa. Teoria \& Educação, 2, 1990; JULIÁ, D. Disciplinas escolares: objetivos, ensino e apropriação. In: LOPES, A. C.; entre outros.

5 Conceito de código disciplinar, apreendido por Cuesta Fernandes, a partir do conceito construído por Hobsbawm (2002), o de "invenção da tradição", entendido como uma "longa tradição social inventada, não de uma vez por todas, mas que vai sendo recriada".

6 Conhecer e Crescer: História; Novo Viver e Aprender História; De Olho no Futuro: História; História, Imagens e Textos; Pelos Caminhos da História; Novo Interagindo com a História; Mundo para Todos: História; Projeto Pitanguá: História; A Escola é Nossa: História; Projeto Buriti: História; Tempo de Aprender: História; Eu Conto História: Minha Infância; Caracol: História; Aprendendo Sempre: História; Asas para Voar: História; Fazer e Aprender História; Aroeira: História; Brasiliana: História; Projeto Conviver: História; Projeto Prosa: História; História Tantas Histórias; Curumim: História; Horizontes: História com Reflexão; Novo Bem-Me-Quer: História; História no Dia a Dia; Conversando sobre História; Hoje é Dia de História; Pensar e Viver: História; Ler o Mundo: História; O Mundo em Movimento: História; História para Crianças; Para Gostar de História.

7 Dissertação de mestrado sob o título: Como os professores e jovens estudantes do Brasil e de Portugal se relacionam com a idéia de África.

$8 \quad 1^{\text {a }}$ edição - 1932.

9 Como indicado nos procedimentos da pesquisa qualitativa o nome da escola não será identificado, bem como, os nomes das professoras são fictícios.

10 Usa-se a nomenclatura adotada na escola, série e ano, na medida em que a Secretaria Municipal de Educação de Curitiba iniciou, em 2007, a implementação gradativa dos 9 anos de escolarização no ensino fundamental.

11 Corregente - professora que atua como auxiliar na sala de aula, especialmente, no acompanhamento de alunos que apresentem dificuldades de aprendizagem.

\section{REFERÊNCIAS}

Abud, K. M. O livro didático e a popularização do saber histórico. In: SiLva, M. A. (Org.). Repensando a história. Rio de Janeiro: Marco Zero, 1984.

Bittencourt, C. M. F. Livros didáticos entre textos e imagens. In: Bittencourt, C. (Org.). O saber histórico na sala de aula. São Paulo: Contexto, 2001. 
Brasil. Lei 10.639, de 9 de janeiro de 2003. Altera a Lei no 9.394, de 20 de dezembro de 1996, que estabelece as diretrizes e bases da educação nacional, para incluir no currículo oficial da Rede de Ensino a obrigatoriedade da temática "História e Cultura Afro-Brasileira”, e dá outras providências. Brasília, Presidência da República, Casa Civil, Subchefia para Assuntos Jurídicos, 9 de jan. 2003.

BRAsIL. LEI No 11.645, DE 10 MARÇO DE 2008. Altera a Lei no 9.394, de 20 de dezembro de 1996, modificada pela Lei $\mathrm{n}^{\circ} 10.639$, de 9 de janeiro de 2003, que estabelece as diretrizes e bases da educação nacional, para incluir no currículo oficial da rede de ensino a obrigatoriedade da temática "História e Cultura Afro-Brasileira e Indígena”. Brasília, Presidência da República, Casa Civil, Subchefia para Assuntos Jurídicos, 10 de mar. 2008.

Brasil. Guia de livros didáticos: PNLD: História. Brasília: Ministério da Educação, Secretaria de Educação Básica, 2009.

Costa Junior, C. PROJETO BURITI: HISTÓRIA. Organizadora Editora Moderna; obra coletiva concebida, desenvolvida e produzida pela Editora Moderna; editor responsável Cesar da Costa Junior. São Paulo: Editora Moderna, 2007.

Cuesta Fernandez, R. Sociogénesis de una disciplina escolar: la Historia. Barcelona: Ediciones Pomares-Corredor, 1997.

Cuesta Fernandez, R. Clío en las aulas: La enseñanza de la Historia en España entre reformas, ilusiones y rutinas. Madrid: Ediciones Akal, 1998.

LEE, P. Progressão da compreensão dos alunos em história. In: BARCA, I. Perspectivas em educação histórica. Actas das Primeiras Jornadas Internacionais de Educação Hist. Braga: Centro de Estudos em Educação e Psicologia, Universidade do Minho, 2001. p.13-27.

LEE, P. “Nós fabricamos carros e eles tinham que andar a pé”: compreensão das pessoas do passado. In: BARCA, I. (Org.) Educação histórica e museus. Actas das Segundas Jornadas Internacionais de Educação Histórica. Braga: Lusografe, 2003. p.19-36.

LEE, P. Putting principles into practice: understanding history. In: BRANSFORD, J. D.; Donovan, M. S. (Eds.). How students learn: history in the classroom. Washington (DC): National Academy Press, 2005.

Medeiros, D. H. A formação da consciência histórica como objetivo do ensino de História no Ensino Médio: o lugar do material didático. Tese (Doutorado em Educação) - Programa de Pós-Graduação em Educação, Linha Cultura, Escola e Ensino, Setor de Educação - Universidade Federal do Paraná, Curitiba. 2005.

RochA, L. C. P. Políticas Afirmativas e Educação: A Lei 10639/03 no Contexto das Políticas Educacionais no Brasil Contemporâneo. 2006. Dissertação (Mestrado em Educação) - Programa de Pós-Graduação em Educação, Linha Políticas e Gestão em Educação, Setor de Educação - Universidade Federal do Paraná, Curitiba. 2006.

Rodrigues, N. Os africanos no Brasil. 4. ed. São Paulo: Editora Nacional; Brasília: INL, 1976. 
RüSEN, J. El libro de texto ideal: reflexiones entorno a los médios para guiar lês clases de historia. In: Revista Nuevas fronteras de la historia. Barcelona: Graó, n.12, año IV, abr. 1997.

RüSEN, J. Razão histórica: teoria da história: fundamentos da ciência histórica. Trad. Estevão de Rezende Martins. Brasília: Editora Universidade de Brasília, 2001.

RÜSEN, J. História viva: teoria da história: formas e funções do conhecimento histórico. Tradução de Estevão de Rezende Martins. Brasília: Editora Universidade de Brasília, 2007.

Schмidt, M. A. Jovens brasileiros e europeus: identidade, cultura e ensino de história (1998-2000). Perspectiva, Florianópolis, v.20, n.Especial, p.183-208, jul./dez. 2002.

Schmidt, M. A. Perspectivas da consciência histórica e da aprendizagem em narrativas de jovens brasileiros. In: ENCONTRO NACIONAL DOS PESQUISADORES DO ENSINO DE HISTÓRIA: NOVOS PROBLEMAS E NOVAS ABORDAGENS, 7., 2006, Belo Horizonte. Anais... Belo Horizonte: FAE/UFMG, 2006.

Schmidt, M. A.; GARCIA, T. M. B. Consciência histórica e crítica em aulas de história. Fortaleza: Secretaria da Cultura do Estado do Ceará/Museu do Ceará, 2006.

Schmidt, M. A.; BARCA, I. Consciência histórica: um diálogo entre países. In: ENCONTRO NACIONAL "PERSPECTIVAS DO ENSINO DE HISTÓRIA", Universidade Federal de Uberlândia, Minas Gerais, Brasil, 2009.

Sobanski, A. Como os professores e jovens estudantes do Brasil e de Portugal se relacionam com a idéia de África. Dissertação (Mestrado em Educação) - Programa de Pós-Graduação em Educação, Linha Cultura, Escola e Ensino, Setor de Educação - Universidade Federal do Paraná, Curitiba. 2008. 